Published in final edited form as:

Behav Res Ther. 2010 June ; 48(6): 459-466. doi:10.1016/j.brat.2010.01.007.

\title{
Maladaptive Coping, Adaptive Coping, and Depressive Symptoms: Variations across Age and Depressive State
}

\author{
Renee J. Thompson, \\ Department of Psychology, Stanford University \\ Jutta Mata, \\ Department of Psychology, Stanford University \\ Susanne M. Jaeggi, \\ Department of Psychology, University of Michigan-Ann Arbor \\ Martin Buschkuehl, \\ Department of Psychology, University of Michigan-Ann Arbor \\ John Jonides, and \\ Department of Psychology, University of Michigan-Ann Arbor \\ Ian H. Gotlib \\ Department of Psychology, Stanford University
}

\begin{abstract}
Rumination has consistently been found to be associated with the onset and duration of major depressive episodes. Little research, however, has examined factors that may weaken the association between maladaptive coping, such as rumination, and depressive symptoms. In three samples of participants, including 149 never-depressed adolescent girls, 41 never-depressed women, and 39 depressed women, we examined whether generally adaptive forms of coping interacted with generally maladaptive coping to predict depressive symptoms. Age-appropriate measures of coping and depression were administered to participants in each sample. In never-depressed females, maladaptive coping / rumination were more strongly related to depressive symptoms in the presence of lower levels of adaptive coping. The relation between depression and maladaptive coping / rumination was weaker in the context of higher levels of adaptive coping. In contrast, for the depressed females, we found main effects for rumination and adaptive coping, with higher levels of rumination and lower levels of adaptive coping being associated with higher levels of depressive symptoms. The present findings highlight how adaptive coping and maladaptive coping, including rumination, differentially relate to each other and depressive symptoms depending on individuals' current depressive state.
\end{abstract}

\section{Keywords}

depression; rumination; responses to stress; coping

\footnotetext{
(C) 2009 Elsevier Ltd. All rights reserved.

Correspondence concerning this article should be addressed to Renee J. Thompson; Department of Psychology; Stanford University; Jordan Hall, Bldg 420; Stanford, CA 94305; reneet@stanford.edu.

Publisher's Disclaimer: This is a PDF file of an unedited manuscript that has been accepted for publication. As a service to our customers we are providing this early version of the manuscript. The manuscript will undergo copyediting, typesetting, and review of the resulting proof before it is published in its final citable form. Please note that during the production process errors may be discovered which could affect the content, and all legal disclaimers that apply to the journal pertain.
} 
Virginia Satir, a prominent clinical therapist, said, "Problems are not the problem; coping is the problem." This statement illustrates that individuals can respond to stressful experiences in both adaptive and maladaptive ways. In fact, people utilize a variety of strategies in responding to stress. It is not clear, however, how adaptive and maladaptive ways of coping interact to predict negative outcomes associated with stress, such as depression (e.g., Brown \& Harris, 1989; Monroe, Slavich, \& Georgiades, 2009).

There is a long history of theory and research concerning the nature of coping (Endler \& Parker, 1990; Fabes \& Eisenberg, 1997; Lazarus \& Folkman, 1984). Investigators differ in how they categorize various forms of coping (e.g., emotion-focused vs. problem-focused coping; approach vs. avoidance; see Skinner, Edge, Altman, \& Sherwood, 2003, for a review). Skinner et al. (2003) argue that it is useful to distinguish among different forms of coping based on whether they are harmful or helpful.

Apart from examining the use of alcohol and illicit substances, research on harmful or maladaptive coping has focused largely on rumination. Almost 30 years of research has documented the adverse effects of rumination, defined as persistent and recurring thoughts focused on one's depressive symptoms and on the implications of those symptoms (Joormann, Dkane, \& Gotlib, 2006; Nolen-Hoeksema, 2000). Rumination has been found to be a relatively stable trait in numerous samples, including college students, community residents, and inpatient populations (see Bagby, Rector, Bacchiochi, \& McBride, 2004, for a review). Rumination has been found to prospectively predict changes in depressive symptoms (e.g., Abela, Aydin, \& Auerbach, 2007).

Rumination has been found to be related to a variety of maladaptive cognitive styles (e.g., negative attributional style). In fact, rumination is sometimes considered to be an exemplar of a broader range of reactions to stressful events, or what Compas and his colleagues (e.g., Connor-Smith, Compas, Wadsworth, Thomsen, \& Saltzman, 2000) refer to as involuntary responses to stress (see also Eisenberg, Fabes, \& Guthrie, 1997). In addition to rumination, other examples of maladaptive coping include emotional numbing, escape, and intrusive thoughts. Not surprisingly, these forms of maladaptive coping have been found to be associated with high levels of psychological distress, such as symptoms of anxiety and depression, in both adolescents (e.g., Jaser et al., 2005; Marcks \& Woods, 2005) and adults (e.g., Morillo, Belloch, \& García-Soriano, 2007; Sarin, Abela, \& Auerbach, 2005).

Although many individuals report experiencing at least mild levels of rumination (e.g., Treynor, Gonzalez, \& Nolen-Hoeksema, 2003), most people do not develop diagnosable depression. Only a few studies have examined factors that may interact with maladaptive coping to decrease the likelihood that they will lead to or exacerbate symptoms of depression. For example, Olson, Hugelshofer, Kwon, and Reff, (2005) found that among undergraduate students, affiliative and self-enhancing forms of humor interacted with rumination to predict dysphoria: among participants with high rumination, those with high adaptive humor had significantly lower levels of dysphoria than did those with low adaptive humor. NolenHoeksema and Davis (1999) found that after the loss of a loved one, higher levels of emotional support were significantly related to reduced depressive symptoms in high, but not in low, ruminators.

In this context, it is important to note that several other forms of coping (e.g., cognitive restructuring, problem-solving coping) have been found to be associated with decreases in psychological distress and better physical health (e.g., Connor-Smith \& Compas, 2004; Hong, 2007). Moreover, a number of cognitive-behavioral interventions focus on teaching depressed individuals specific forms of adaptive coping. For example, in the Depression Prevention Course, depressed individuals are taught to identify negative or destructive thoughts and 
replace them with positive or constructive thoughts (i.e., cognitive restructuring; Muñoz, 1984/1998). Similarly, Problem-Solving Therapy focuses on helping depressed patients learn to identify and resolve problems (D'Zurilla \& Nezu, 2006; Nezu, Nezu, \& Perri, 1998). It is possible, therefore, that these other forms of adaptive coping will diminish the association between maladaptive coping and symptoms of depression.

The present study was designed to examine whether forms of adaptive coping interact with maladaptive coping, including rumination, to predict levels of depressive symptoms. To address this question, we examined the associations among forms of adaptive coping, maladaptive coping, and depressive symptoms in three samples of females: one sample of never-depressed girls, one sample of never-depressed adult women, and one sample of currently depressed adult women. We examined samples of adolescents and adults in part because of evidence that the tendency to ruminate increases with age (Hampel \& Petermann, 2005). Moreover, because depressed mood have been found to be associated with changes in rumination (e.g., Kasch, Klein, \& Lara, 2001; Kuehner \& Weber, 1999), we assessed adolescents and adults with no history of Major Depressive Disorder (MDD). Finally, we also included a sample of currently depressed women in order to examine our hypotheses in a clinical sample. We hypothesized that regardless of age or depressive state, maladaptive coping, such as rumination, would be less strongly related to depressive symptoms in the context of higher levels of adaptive coping.

\section{Method}

\section{Participants}

Sample 1-Participants in this sample were 149 girls between the ages of nine and 14 ( $M=$ 12.1 years, $S D=1.5$ years) with no current or past history of mental health disorders. Of those who reported race/ethnicity $(\mathrm{n}=143)$, the majority of girls were Caucasian $(72.7 \%)$; of the remaining girls, 9.8\% were biracial, 9.1\% were Asian American, 5.6\% were Latina, and 2.8\% were African American. Of those who reported pubertal status ( $\mathrm{n}=108)$, approximately 50\% $(\mathrm{n}=55)$ had had their first menses. Approximately $35 \%$ of the girls $(\mathrm{n}=52)$ had mothers with a recurrent history of depression as assessed by clinical interview (high-risk); the remaining $65 \%$ of the girls $(\mathrm{n}=97)$ had mothers who had no history of any mental health disorders (lowrisk) ${ }^{1}$. Through advertisements posted in numerous locations within the local community, these girls and their mothers were recruited to participate in a larger project on how people process information (cf. Joormann, Talbot, \& Gotlib, 2007). Mothers completed a telephone screening to establish that both mothers and daughters were fluent in English and to assess whether the mother-daughter pair might be eligible for participation. Mothers provided written informed consent, and daughters provided written assent. Mother-daughter pairs were compensated \$25 per hour for their participation.

Daughters and mothers were administered a structured clinical interview about the daughters, the Schedule for Affective Disorders and Schizophrenia for School-Age Children-Present and Lifetime version (K-SADS-PL; Kaufman, Birmaher, Brent, Ryan, \& Rao, 2000). To be eligible for participation, both informants needed to report an absence of any current or past mental health disorders in the daughters. Interviewers were blind to participants' reports of maladaptive and adaptive coping.

Sample 2-Participants in this sample were 41 women between the ages of 18 and $45(M=$ 27.2 years, $S D=7.0$ years). All participants were native English speakers. Of those who

\footnotetext{
${ }^{1} \mathrm{We}$ did not assess history of depression in the girls' fathers. It is possible, therefore, that some of the low-risk girls may actually be at an increased familial risk for depression based on their fathers', but not on their mothers', history of depression.
} 
reported their ethnicity/race ( $\mathrm{n}=39)$, the majority of women were Caucasian $(66.7 \%) ; 12.8 \%$ were Asian American, 2.6\% were Latina, $15.4 \%$ were African American; and 2.6\% were Native American. Trained interviewers administered the Structured Clinical Interview for DSM-IV Axis I Disorders (SCID-I; First, Spitzer, Gibbon, \& Williams, 2001) to examine participants current and past mental health. Participants had no current or past history of Axis I disorders. The SCID-I interviewers were blind to participants' levels of adaptive coping and rumination. Participants were recruited through advertisements posted online (e.g., Craigslist) and at local agencies and businesses in the community (e.g., bulletin boards). Participants provided informed consent and were compensated \$25 per hour for their participation.

Sample 3-Participants in this sample were 39 depressed women between the ages of 18 and $40(M=27.7$ years, $S D=6.6$ years $)$. All participants were native English speakers. Of those who reported their race/ethnicity $(\mathrm{n}=36)$, the majority of women were Caucasian $(69.4 \%)$; 13.9\% were biracial, $2.8 \%$ were Asian American/Pacific Islander, $2.8 \%$ were Latina, 5.6\% were African American, 2.8\% were Native American, and 2.8\% indicated the category of "other". Trained interviewers administered the SCID-I (First et al., 2001) to examine participants' current and past mental health. All women met criteria for current major depressive episode. Individuals were not eligible for participation if they met criteria for Bipolar Disorder, or if they met criteria for any psychotic disorders or any substance dependence in the last six months. The SCID-I interviewers were blind to participants' levels of adaptive coping and rumination. Participants provided informed consent and were compensated $\$ 25$ per hour for their participation.

\section{Materials}

Age-appropriate questionnaires and interviews assessing adaptive coping, maladaptive coping, and depressive symptoms were administered to all samples.

Maladaptive coping-Girls' maladaptive coping was assessed using the 60-item Responses to Stress Questionnaire (RSQ; Connor-Smith et al., 2000), a five-factor scale that has been validated in several samples of adolescents. The RSQ was designed to assess adolescents' responses to stress to a relevant domain such as social stress, family conflict, economic strain, or pain (Connor-Smith et al., 2000). For this study, the measure focused on responses to conflicts with their mothers. Participants indicated on a 4-point scale the extent to which they have engaged in behaviors or feelings when they have had problems with their mothers. For the present study, two factors were computed that Connor-Smith et al. (2000) labeled as involuntary engagement and involuntary disengagement. Involuntary engagement includes items assessing rumination, intrusive thoughts, physiological arousal, emotional arousal, and involuntary action (e.g., "When problems with my family come up, I can't stop thinking about how I'm feeling"). Involuntary disengagement includes items assessing emotional numbing, cognitive interferences, inaction, and escape (e.g., "My mind goes blank when I have problems with my family, I can't think at all"). The total score for each factor was computed. Because the two factors in the original factor analyses were correlated at 90 (Connor-Smith et al., 2000), we combined the two factors to yield a single measure of maladaptive coping. The internal consistency of this measure was $\alpha=.91$.

To assess the women's maladaptive coping, these participants completed a 10-item subset of the Ruminative Responses Scale (RRS; Joormann et al., 2006; Treynor et al., 2003): five items from the reflective pondering subscale and five items from the brooding subscale. ${ }^{2}$ Participants

\footnotetext{
${ }^{2}$ Investigators have computed a two-factor model of rumination: brooding and reflective pondering (Joormann et al., 2006; Treynor et al., 2003). We assessed brooding and reflective pondering, but found the direction of the results to be similar for both factors. Consequently, we used the total rumination score in this study.
} 
indicated on an 4-point scale the extent to which they engage in a series of responses when they are experiencing a sad mood. An example brooding item includes "Think 'Why do I always react this way?", and an example of a reflective pondering item is "Analyze recent events to try to understand why you are depressed." A total score for rumination was computed. Adequate internal consistency and retest-reliabilities for the RRS have been reported (Treynor et al., 2003). Internal consistency for Sample 2 was $\alpha=.80$ and for Sample 3 was $\alpha=.76$.

Adaptive coping-Girls' use of adaptive coping was assessed using the RSQ (Connor-Smith et al., 2000). For the present study, two factors that represent adaptive forms of coping were computed that Connor-Smith et al. (2000) labeled (1) primary control, composed of problem solving, emotional regulation, and emotional expression scales; and (2) secondary control, composed of cognitive restructuring, positive thinking, acceptance, and distraction scales. According to Connor-Smith et al. (2000), primary control coping alters the objective conditions such as the stressor or one's emotional response to the stressor. An example item from the primary control coping factor is, "I try to think of different ways to change the problem or fix the situation." Secondary control coping helps the individual to adapt to the problem. An example item from the secondary control coping factor is, "I tell myself everything will be alright." Connor-Smith et al. found these two factors to be negatively associated with internalizing symptoms in adolescents. Again, the total score for each factor was computed. The internal consistencies for primary and secondary control coping in the present study were $\alpha \mathrm{s}=.78$ and .79 , respectively.

For Samples 2 and 3, women's use of adaptive coping was assessed using their responses to scales from two different questionnaires: the COPE (Carver, Scheier, \& Weintraub, 1989), and the Emotional Approach Coping Scales (EAC; Stanton, Kirk, Cameron \& Dannoff-Burg, 2000). Women completed three 4-item scales from the COPE: Active Coping, Planning, and Positive Reinterpretation and Growth. Items include "I concentrate my efforts on doing something about it," (Active Coping); "I try to come up with a strategy about what to do," (Planning); and "I look for something good in what is happening," (Positive Reinterpretation \& Growth). Participants also completed the 4-item Emotional Processing scale from the EAC. An item from Emotional Processing is "I take the time to figure out what I'm really feeling." Participants rated the extent to which they respond to stressful events in a given manner ( 1 = I usually don't do this at all, $4=$ I usually do this a lot $)$. The two scales of Active Coping and Planning formed a single factor in the original article validating the scale (Carver et al., 1989), and were combined here to assess what we have labeled as problemsolving coping. Internal consistency for problem-solving coping for both adult samples was $\alpha=$.93. The remaining two scales, Positive Reinterpretation and Growth and Emotional Processing, reflect participants' efforts to better understand and recast a problem in a more positive light; we combined these scales and labeled the resulting measure 'cognitive restructuring.' Internal consistency for adult cognitive restructuring for Sample 2 was $\alpha=.85$, and for Sample 3 was $\alpha=.81$.

Depressive symptoms-Girls completed the 10-item form of the Children's Depression Inventory (CDI-S; Kovacs, 1985). This widely-used self-report instrument was designed to assess depressive symptoms in children between the ages of 8 and 17. Participants indicated which of a series of statements best described how they have been feeling recently. Internal consistency for the girls was $\alpha=.75$.

For Samples 2 and 3, women's levels of depressive symptoms were assessed using the Beck Depression Inventory-II (BDI-II; Beck, Steer, \& Brown, 1996; Steer, Ball, Ranieri, \& Beck, 1999). The BDI-II is a self-report measure that consists of 21 groups of statements describing various depressive symptoms (e.g., loss of pleasure, suicidal thoughts). For each group of statements, participants choose the one that best reflects the degree to which they felt that 
symptom over the past two weeks. This measure has been shown to have good reliability and validity (Beck et al., 1996; Steer et al., 1999). Internal consistency for depressive symptoms for Sample 2 was $\alpha=.76$, and for Sample 3 was $\alpha=.90$.

\section{Results}

\section{Correlations among constructs and descriptive statistics}

Comparisons between the girls based on depression risk and between the two adult female samples are presented in Table 1. Girls did not differ in age, either form of adaptive coping, but, compared to low-risk girls, high-risk girls reported significantly higher levels of depressive symptoms and maladaptive coping. Nondepressed and depressed women did not differ in age, but depressed women reported higher levels of depressive symptoms and rumination, and lower levels of both forms of adaptive coping, than did nondepressed women. Correlations among independent and dependent variables for the three samples are presented in Table 2.

\section{Adaptive and maladaptive coping}

We hypothesized that maladaptive coping would be less strongly related to depressive symptoms in the context of high levels of adaptive coping. To test this hypothesis, we conducted two hierarchical multiple regression analyses with each sample predicting participants' level of depressive symptoms (for adolescents: one with primary control coping and one with secondary control coping; for adults: one with problem-solving coping and one with cognitive restructuring). Centered scores were used in all analyses (Aiken \& West, 1991). In the first step of each equation, we entered one form of adaptive coping and maladaptive coping. In the second step, we entered the two-way interaction of these variables (e.g., primary control coping by maladaptive coping).

\section{Adolescent sample ${ }^{3}$}

We first regressed girls' depressive symptoms on primary control coping, maladaptive coping, and their interaction. As predicted, the interaction of primary control coping and maladaptive coping significantly predicted girls' depressive symptoms level above and beyond the contribution of the individual constructs. See Table 3 for the standardized regression coefficients and the significance tests for individual regression coefficients. The interaction term, $\beta=-.35, t=-4.49, p<.01$, indicated that as primary control coping decreases, higher levels of maladaptive coping were associated with higher levels of depressive symptoms. Following the recommendations of Cohen, Cohen, West, and Aiken (2003), we used unstandardized beta weights and 1.0 and -1.0 standard deviation values to predict high and low levels of depressive symptoms, which were z-scored to allow comparison between samples. The relations among maladaptive coping, primary control coping, and depressive symptoms are presented graphically in Figure 1. The effects of maladaptive coping on depressive symptoms varied as a function of primary control coping. Specifically, maladaptive coping were more strongly related to depression in the context of low levels of primary control coping than among high levels of primary control coping.

Next, we regressed girls' depressive symptoms on secondary control coping, maladaptive coping, and their interaction. As shown in Table 3, the interaction of secondary control coping and maladaptive coping significantly predicted depressive symptoms. As with primary control coping, the interaction term, $\beta=-.16, t=-1.93, p=.056$, suggested that as secondary control

\footnotetext{
${ }^{3}$ By conducting two multiple regressions, we tested whether relations between adaptive forms of coping, rumination, and depressive symptoms varied by group (i.e., low- vs. high-risk for depression). Neither three-way interaction predicting depressive symptoms was significant: (a) primary control by maladaptive coping by group, $\beta=.06, t=.60, n s$; (b) primary control by maladaptive coping by group, $\beta=-.05, t=-.49, n s$.
} 
coping decreases, higher levels of maladaptive coping are associated with higher levels of depressive symptoms (see Figure 1 for a graphical representation of these relations), although the significance of the interaction term is only marginal. The effects of maladaptive coping on depressive symptoms varied as a function of secondary control coping, with maladaptive coping being more strongly associated with depressive symptoms in the context of low levels of secondary control coping than in the context of high levels of secondary control coping.

\section{Nondepressed adult sample}

Next, we examined the relations among one type of maladaptive response to stress, rumination, forms of adaptive coping (i.e., problem-solving coping and cognitive restructuring), and women's depressive symptoms. As we did for the adolescent sample above, we regressed depressive symptoms on (a) problem-solving coping, rumination, and their interaction; and (b) cognitive restructuring, rumination, and their interaction. As shown in Table 4, the interaction term explained significant variance above and beyond the individual terms for problem-solving coping. For cognitive restructuring, the interaction term was marginally significant. Again, we used unstandardized beta weights and 1.0 and -1.0 standard deviation values to predict high and low levels of depressive symptoms, which are presented in Figure 2. The effects of rumination on depressive symptoms varied as a function of women's level of adaptive coping. The relation between rumination and depressive symptoms was stronger when levels of adaptive coping (both problem-solving coping and cognitive restructuring) were low.

\section{Depressed adult sample}

Next, we examined the relations among rumination, forms of adaptive coping (i.e., problemsolving coping and cognitive restructuring), and depressive symptoms in the sample of depressed women. As we did for the nondepressed adult sample, we regressed depressive symptoms on (a) problem-solving coping, rumination, and their interaction; and (b) cognitive restructuring, rumination, and their interaction. As shown in Table 5, neither interaction term explained variance above and beyond the individual effects of each variable. Instead, both analyses yielded main effects for rumination, with higher levels of rumination associated with higher levels of depressive symptoms. The main effect for problem-solving coping was marginally significant, and the main effect for cognitive restructuring was significant, with problem-solving coping and cognitive restructuring inversely related to depressive symptoms. Again, we used unstandardized beta weights and 1.0 and -1.0 standard deviation values to predict high and low levels of depressive symptoms, which are presented in Figure 3.

\section{Discussion}

In this study we examined whether adaptive coping in the presence of maladaptive coping was associated with lower levels of depressive symptoms in three distinct samples of participants: nondepressed adolescent girls, nondepressed women, and depressed women. Our central hypothesis was supported in both nondepressed samples: the associations between depressive symptoms and maladaptive coping (adolescent sample) / rumination (adult sample) depended on the level of adaptive coping, such that the relation between maladaptive coping / rumination and depression was stronger when levels of adaptive coping were low. This pattern was evident for both forms of adaptive coping in both the nondepressed adolescents and the nondepressed adults. High levels of adaptive coping appeared to act as a protective factor in the presence of maladaptive coping such as rumination.

Our results indicate that adaptive coping is important for nondepressed adolescent girls, independent of familial risk for depression, extending work by Hampel and Petermann (2005), who compared levels of coping in children and adolescents. Although children and adolescents in that study did not differ in their use of the form of coping that was most reflective 
of primary control coping (i.e., situational control), adolescents reported higher levels of rumination than did children. The present investigation demonstrates that in both adolescents and adults, adaptive coping functions to reduce depressive symptoms in the presence of such maladaptive coping as rumination.

Previous findings concerning the associations between psychological distress and adaptive forms of coping across adolescent and adult studies have been mixed. Similar to our findings with our adolescent sample, other investigators have not obtained a significant relation between psychological distress and either primary control (Jaser et al., 2007; Langrock, Compas, Keller, Merchant, \& Copeland, 2002; Silk, Steinberg, \& Morris, 2003) or secondary control (Silk et al., 2003; Connor-Smith \& Compas, 2004). Thus, these forms of generally adaptive coping may be related to depressive symptoms only in the context of higher levels of rumination, as we found in the adolescent sample. And similar to our findings in the adult samples, problemsolving coping is not always associated with decreased psychological distress in the adult literature (Skinner et al., 2003). Other researchers, however, have reported a significant relation between primary control and psychological distress (e.g., Connor-Smith \& Compas, 2002; Connor-Smith et al., 2000) as well as between secondary control and psychological distress, as we found in the depressed adults (e.g., Connor-Smith \& Compas, 2002; Langrock et al., 2002). It is clear, therefore, that much more work needs to be done to elucidate the nature of the relations among adaptive and maladaptive coping and psychological distress.

The present finding that adaptive coping appears to interact with rumination and maladaptive coping is relevant to Nolen-Hoeksema's response styles theory (e.g., Nolen-Hoeksema, 1991; Nolen-Hoeksema et al., 2008). One of the mechanisms through which Nolen-Hoeksema theorized that rumination exacerbated depression was by interfering with effective problemsolving; indeed, Morrow and Nolen-Hoeksema (1990) and Watkins and Baracaia (2002) provided empirical support for this formulation. The results of the present study complement these findings by indicating that in the presence of adaptive forms of coping, the relation between rumination and depressive symptoms is weakened for individuals without diagnosable MDD. As noted earlier, rumination has been found to be a relatively stable trait; thus, identifying mechanisms that reduce the expression of this trait is a promising step toward decreasing risk of depression. To test the direction of causality, however, future research will have to use an experimental or longitudinal design, perhaps utilizing experience sampling methodologies, which would also minimize biases inherent with retrospective reports of adaptive coping (e.g., Stone et al., 1999).

The central hypothesis of this study was supported in two samples of nondepressed females. In both nondepressed samples, findings were stronger when examining the form of adaptive coping that included problem-solving than for the form that included cognitive restructuring. The strength of the two interactions of adaptive coping and rumination were more similar in the nondepressed adults then they were in the nondepressed adolescents. Generalizability of the findings may be limited because of the relatively small size of the nondepressed adult sample.

In contrast with the results from the two nondepressed samples, our central hypothesis was not supported in our sample of depressed women. Instead, for depressed women, higher levels of both forms of adaptive coping were associated with lower levels of depressive symptoms, and higher levels of rumination were associated with higher levels of depressive symptoms. Future research is needed to examine why, for depressed women, the relation between adaptive forms of coping and depressive symptoms were not contingent on rumination, and why the relation between rumination and depressive symptoms were not contingent on adaptive forms of coping. 
Although not examined specifically in this paper, it is possible that the differences we obtained between depressed and nondepressed participants are due to the strength or the temporal nature of coping. For example, individuals without MDD may realize that they are ruminating and switch to a more adaptive form of coping. This switch may be sufficient to improve their mental state and keep them from exacerbating their negative affect. In contrast, when depressed individuals ruminate, it is likely that they have difficulty engaging more adaptive forms of coping, either because the intensity of their rumination is stronger than it is in nondepressed persons, or because they have fewer adaptive coping resources. In fact, investigators have found that depressed individuals cannot easily inhibit negative thoughts and remove negative material from working memory (e.g., Joormann \& Gotlib, 2008; Joormann et al., in press), making it difficult for them to disengage with rumination and cope more adaptively.

Other aspects of this study also warrant attention. First, whereas we examined a broad range of maladaptive coping in the adolescent sample, we assessed a specific form of maladaptive stress response, rumination, in the adult samples. Although findings in both nondepressed samples were similar regardless of the specificity of our measure of maladaptive coping, future research should examine whether the results replicate when examining other forms of maladaptive coping (e.g., emotional numbing, escape) in adult samples. Second, as we noted earlier, although some researchers (e.g., Connor-Smith et al., 2000; Hartlage, Alloy, Vázquez \& Dykman, 1993) have conceptualized such maladaptive coping as rumination as 'involuntary,' other investigators have ignored the degree to which coping might be involuntary or automatic (e.g., Carver et al., 1989). Consequently, the automaticity of adaptive and maladaptive coping remains an empirical question. Third, because we assessed only females in this study; we do not know, therefore, whether these results generalize to boys and/or men. This is a particularly important question because investigators have documented gender differences in coping (e.g., Kelly, Tyrka, Price, \& Carpenter, 2008; Matud, 2004) and rumination (e.g., Nolen-Hoeksema, Larson, \& Grayson, 1999). It remains for future research, therefore, to examine the nature of the association between adaptive coping and rumination in males. Finally, although investigators have distinguished between two factors of rumination, brooding and reflective pondering (e.g., Treynor et al., 2003), we found that these two factors interacted similarly with adaptive coping to predict depressive symptoms. It will be important in future studies to examine whether these two rumination factors are more strongly distinguishable in predicting other forms of psychopathology.

In sum, the present study builds on and expands both theoretical and empirical work examining adaptive coping, maladaptive coping, and depression. The findings of this study highlight how rumination and coping are differentially related to each other depending on individuals' current depressive state, and how this pattern appears to be stable from adolescence to adulthood. Indeed, lower levels of maladaptive coping, in combination with higher levels of adaptive coping, may explain the resilience of our nondepressed participants.

\section{Acknowledgments}

The authors thank Hannah Burley, Sarah Victor, and Yamanda Wright for their help with this study. This research was supported by NIMH grants MH74849 and MH59259 to IHG and NIMH grant MH60655 to JJ.

\section{References}

Abela JRZ, Aydin CM, Auerbach RP. Responses to depression in children: Reconceptualizing the relation among response styles. Journal of Abnormal Child Psychology 2007;35:913-927. doi:10.1007/ s10802-007-9143-2. [PubMed: 17549619]

Aiken, LS.; West, SG. Multiple regressions: Testing and interpreting interactions. Sage Publications, Inc.; Thousand Oaks, CA: 1991. 
Bagby RM, Rector NA, Bacchiochi JR, McBride C. The stability of the Response Styles Questionnaire Rumination Scale in a sample of patients with major depression. Cognitive Therapy and Research 2004;28:527-538. doi:10.1023/B:COTR.0000045562.17228.29.

Beck, AT.; Steer, RA.; Brown, GK. Manual for the Beck Depression Inventory-II. Psychological Corporation; San Antonio, TX: 1996.

Brown, GQ.; Harris, TO. Life events and illness. Guilford Press; New York, NY: 1989.

Carver CS, Scheier MF, Weintraub JK. Assessing coping strategies: A theoretically based approach. Journal of Personality and Social Psychology 1989;56:267-283. doi:10.1037/0022-3514.56.2.267. [PubMed: 2926629]

Cohen, J.; Cohen, P.; West, SG.; Aiken, LS. Applied multiple regression/correlation analysis for the behavioral sciences. 3rd ed. Lawrence Erlbaum Associates; Mahwah, NJ: 2003.

Connor-Smith JK, Compas BE. Vulnerability to social stress: Coping as a mediator or moderator of sociotropy and symptoms of anxiety and depression. Cognitive Therapy and Research 2002;26:3955. doi:10.1023/A:1013889504101.

Connor-Smith JK, Compas BE. Coping as a moderator of relations between reactivity to interpersonal stress, health status, and internalizing problems. Cognitive Therapy and Research 2004;28:347-368. doi:10.1023/B:COTR.0000031806.25021.d5.

Connor-Smith JK, Compas BE, Wadsworth ME, Thomsen AH, Saltzman H. Responses to stress in adolescence: Measurement of coping and involuntary stress responses. Journal of Consulting and Clinical Psychology 2000;68:976-992. doi:10.1037/0022-006X.68.6.976. [PubMed: 11142550]

D'Zurilla, TD.; Nezu, AM. Problem-solving therapy: A positive approach to clinical intervention. 3rd ed. Springer Publishing Co.; New York, NY: 2006.

Eisenberg, N.; Fabes, RA.; Guthrie, IK. Coping with stress: The roles of regulation and development. In: Wolchik, SA.; Sandler, IN., editors. Handbook of children's coping: Linking theory and intervention. Plenum Press; New York, NY: 1997. p. 41-70.

Endler NS, Parker JD. Multidimensional assessment of coping: A critical evaluation. Journal of Personality and Social Psychology 1990;58:844-854. doi:10.1037/0022-3514.58.5.844. [PubMed: 2348372]

Fabes RA, Eisenberg N. Regulatory control and adults' stress related responses to daily life events. Journal of Personality and Social Psychology 1997;73:1107-1117. doi:10.1037/0022-3514.73.5.1107. [PubMed: 9364764]

First, MB.; Spitzer, RL.; Gibbon, M.; Williams, JBW. The Structured Clinical Interview for DSM-IVTR Axis I disorders. NY State Psychiatric Institute, Biometrics Research; New York: 2001.

Hampel P, Petermann F. Age and gender effects on coping in children and adolescents. Journal of Youth and Adolescence 2005;34:73-83. doi:10.1007/s10964-005-3207-9.

Hartlage S, Alloy LB, Vázquez C, Dykman B. Automatic and effortful processing in depression. Psychological Bulletin 1993;113:247-278. doi:10.1037/0033-2909.113.2.247. [PubMed: 8451334]

Hong RY. Worry and rumination: Differential associations with anxious and depressive symptoms and coping behavior. Behaviour Research and Therapy 2007;45:277-290. doi:10.1016/j.brat. 2006.03.006. [PubMed: 16635479]

Jaser SS, Langrock AM, Keller G, Merchant MJ, Benson MA, Reeslund K, et al. Coping with the stress of parental depression II: Adolescent and parent reports of coping and adjustment. Journal of Clinical Child and Adolescent Psychology 2005;34:193-205. doi:10.1207/s15374424jccp3401_18. [PubMed: 15677293]

Jaser SS, Champion JE, Reeslund KL, Keller G, Merchant MJ, Benson M, Compas BE. Cross-situational coping with peer and family stressors in adolescent offspring of depressed parents. Journal of Adolescence 2007;30:917-932. doi:10.1016/j.adolescence.2006.11.010. [PubMed: 17241658]

Joormann J, Dkane M, Gotlib IH. Adaptive and maladaptive components of rumination? Diagnostic specificity and relation to depressive biases. Behavior Therapy 2006;37:269-280. doi:10.1016/j.beth. 2006.01.002. [PubMed: 16942978]

Joormann J, Gotlib IH. Updating the contents of working memory in depression: Interference from irrelevant negative material. Journal of Abnormal Psychology 2008;117:182-192. doi: 10.1037/0021-843X.117.1.182. [PubMed: 18266496] 
Joormann J, Nee DE, Berman MG, Jonides J, Gotlib IH. Interference resolution in major depression. Cognitive, Affective, and Behavioral Neuroscience. (in press).

Joormann J, Talbot L, Gotlib IH. Biased processing of emotional information in girls at risk for depression. Journal of Abnormal Psychology 2007;116:135-143. doi:10.1037/0021-843X. 116.1.135. [PubMed: 17324024]

Kasch KL, Klein DN, Lara ME. A construct validation study of the Response Style Questionnaire Rumination scale in participants with a recent-onset major depressive episode. Psychological Assessment 2001;13:375-383. doi:10.1037/1040-3590.13.3.375. [PubMed: 11556274]

Kaufman J, Birmaher B, Brent DA, Ryan ND, Rao U. K-SADS-PL. Journal of the American Academy of Child and Adolescent Psychiatry 2000;39:980-988. doi:10.1097/00004583-200010000-00002.

Kelly MM, Tyrka AR, Price LH, Carpenter LL. Sex differences in the use of coping strategies: Predictors of anxiety and depressive symptoms. Depression and Anxiety 2008;25:839-846. doi:10.1002/da. 20341. [PubMed: 17603810]

Kovacs M. The Children's Depression Inventory (CDI). Psychopharmacology Bulletin 1985;21:9951124. [PubMed: 4089116]

Kuehner C, Weber I. Responses to depression in unipolar depressed patients: An investigation of NolenHoeksema's response style theory. Psychological Medicine 1999;29:1323-1333. doi:10.1017/ S0033291799001282. [PubMed: 10616938]

Lazarus, RS.; Folkman, S. Stress, appraisal, and coping. Springer; New York, NY: 1984.

Langrock AM, Compas BE, Keller G, Merchant MJ, Copeland ME. Coping with the stress of parental depression: Parents' reports of children's coping, emotional, and behavioral problems. Journal of Clinical Child and Adolescent Psychology 2002;31:312-324. doi:10.1207/ S15374424JCCP3103_03. [PubMed: 12149969]

Marcks BA, Woods DW. A comparison of thought suppression to an acceptance-based technique in the management of personal intrusive thoughts: A controlled evaluation. Behaviour Research and Therapy 2005;43:433-445. doi:10.1016/j.brat.2004.03.005. [PubMed: 15701355]

Matud MP. Gender differences in stress and coping styles. Personality and Individual Differences 2004;37:1401-1415. doi:10.1016/j.paid.2004.01.010.

Monroe, SM.; Slavich, GM.; Georgiades, K.; Handbook, of depression. The social environment and life stress in depression. 2nd ed. Gotlib, IH.; Hammen, CL., editors. Guilford Press; New York: 2009. p. 340-360.

Morillo C, Belloch A, García-Soriano G. Clinical obsessions in obsessive-compulsive patients and obsession-relevant intrusive thoughts in non-clinical, depressed and anxious subjects: Where are the differences? Behaviour Research and Therapy 2007;45:1319-1333. doi:10.1016/j.brat.2006.11.005. [PubMed: 17208197]

Morrow J, Nolen-Hoeksema S. Effects of responses to depression on the remediation of depressive affect. Journal of Personality and Social Psychology 1990;58:519-527. doi:10.1037/0022-3514.58.3.519. [PubMed: 2324941]

Muñoz, RF. The depression prevention course. University of California; San Francisco: 1984/1998. Unpublished manuscript

Nezu, AM.; Nezu, CM.; Perri, MG. Problem-solving therapy for depression. John Wiley \& Sons, Inc.; New York, NY: 1998.

Nolen-Hoeksema S. Responses to depression and their effects on the duration of depressive episodes. Journal of Abnormal Psychology 1991;100:569-582. doi:10.1037/0021-843X.100.4.569. [PubMed: 1757671]

Nolen-Hoeksema S. The role of rumination in depressive disorders and mixed anxiety/depressive symptoms. Journal of Abnormal Psychology 2000;109:504-511. doi:10.1037/0021-843X. 109.3.504. [PubMed: 11016119]

Nolen-Hoeksema S, Davis CG. "Thanks for sharing that": Ruminators and their social support networks. Journal of Personality and Social Psychology 1999;77:801-814. doi:10.1037/0022-3514.77.4.801. [PubMed: 10531672]

Nolen-Hoeksema S, Harrell ZA. Rumination, depression, and alcohol use: Tests of gender differences. Journal of Cognitive Psychotherapy 2002;16:391-403. doi:10.1891/jcop.16.4.391.52526. 
Nolen-Hoeksema S, Larson J, Grayson C. Explaining the gender differences in depressive symptoms. Journal of Personality and Social Psychology 1999;77:1061-1072. doi: 10.1037/0022-3514.77.5.1061. [PubMed: 10573880]

Olson ML, Hugelshofer DS, Kwon P, Reff RC. Rumination and dysphoria: The buffering role of adaptive forms of humor. Personality and Individual Differences 2005;39:1419-1428. doi:10.1016/j.paid. 2005.05.006.

Sarin S, Abela JRZ, Auerbach RP. The response styles theory of depression: A test of specificity and causal mediation. Cognition and Emotion 2005;19:751-761.

Silk JS, Steinberg L, Morris AS. Adolescents' emotion regulation in daily life: Links to depressive symptoms and problem behavior. Child Development 2003;74:1869-1880. doi:10.1046/j. 1467-8624.2003.00643.x. [PubMed: 14669901]

Skinner EA, Edge K, Altman J, Sherwood H. Searching for the structure of coping: A review and critique of category systems for classifying ways of coping. Psychological Bulletin 2003;129:216-269. doi: 10.1037/0033-2909.129.2.216. [PubMed: 12696840]

Stanton AL, Kirk SB, Cameron CL, Danoff-Burg S. Coping through emotional approach: Scale construction and validation. Journal of Personality and Social Psychology 2000;78:1150-1169. doi: 10.1037/0022-3514.78.6.1150. [PubMed: 10870915]

Steer RA, Ball R, Ranieri WF, Beck AT. Dimensions of the Beck Depression Inventory-II in clinically depressed outpatients. Journal of Clinical Psychology 1999;55:117-128. doi:10.1002/(SICI) 1097-4679(199901)55:1<117::AID-JCLP12>3.0.CO;2-A. [PubMed: 10100838]

Stone AA, Schwartz JE, Neale JM, Shiffman S, Marco CA, Hickcox M, Paty J. A comparison of coping assessed by ecological momentary assessment and retrospective recall. Journal of Personality and Social Psychology 1999;74:1670-1680. doi:10.1037/0022-3514.74.6.1670. [PubMed: 9654765]

Treynor W, Gonzalez R, Nolen-Hoeksema S. Rumination reconsidered: A psychometric analysis. Cognitive Therapy and Research 2003;27:247-259. doi:10.1023/A:1023910315561.

Watkins E, Baracaia S. Rumination and social problem-solving in depression. Behaviour Research and Therapy 2002;40:1179-1189. doi:10.1016/S0005-7967(01)00098-5. [PubMed: 12375726] 

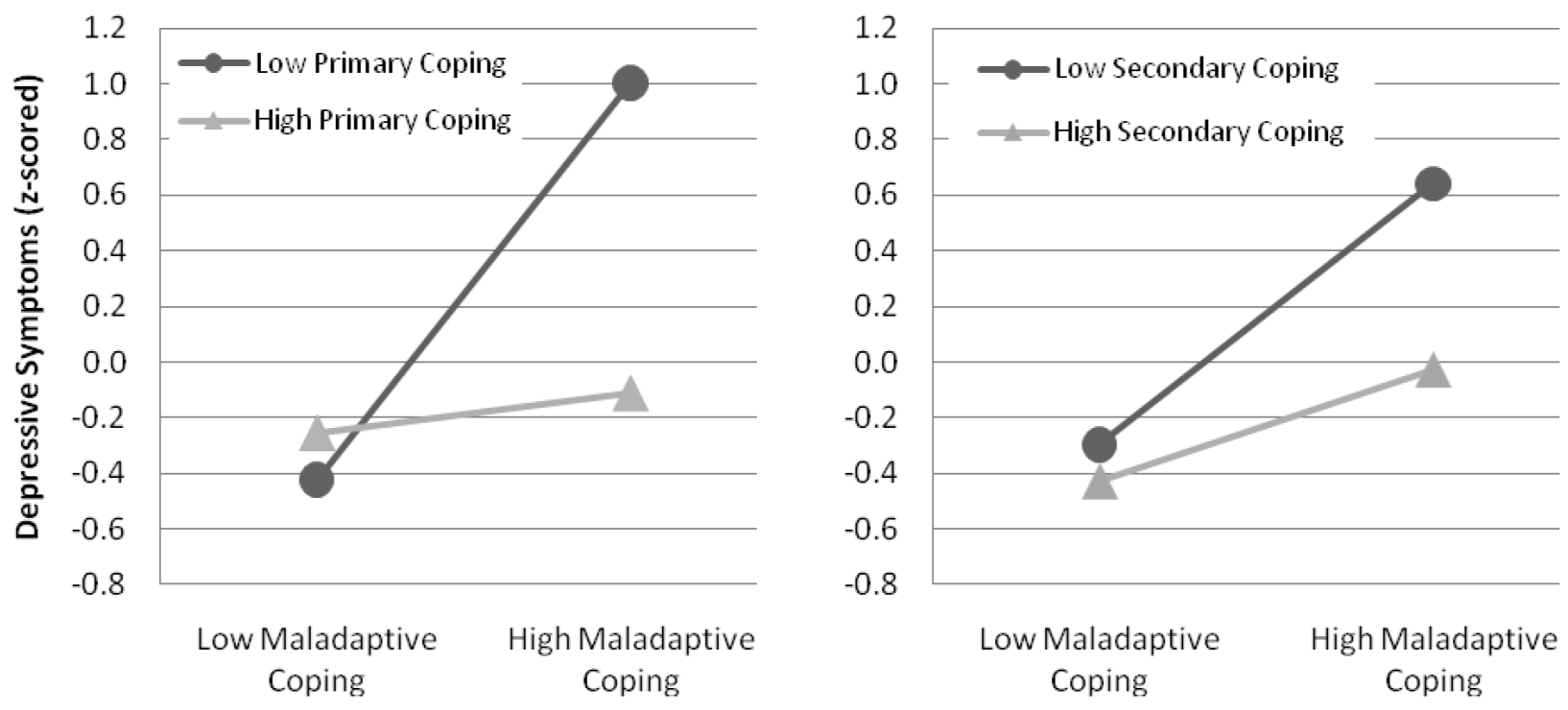

Figure 1.

Adaptive coping by maladaptive coping predicting depressive symptoms in nondepressed adolescents 

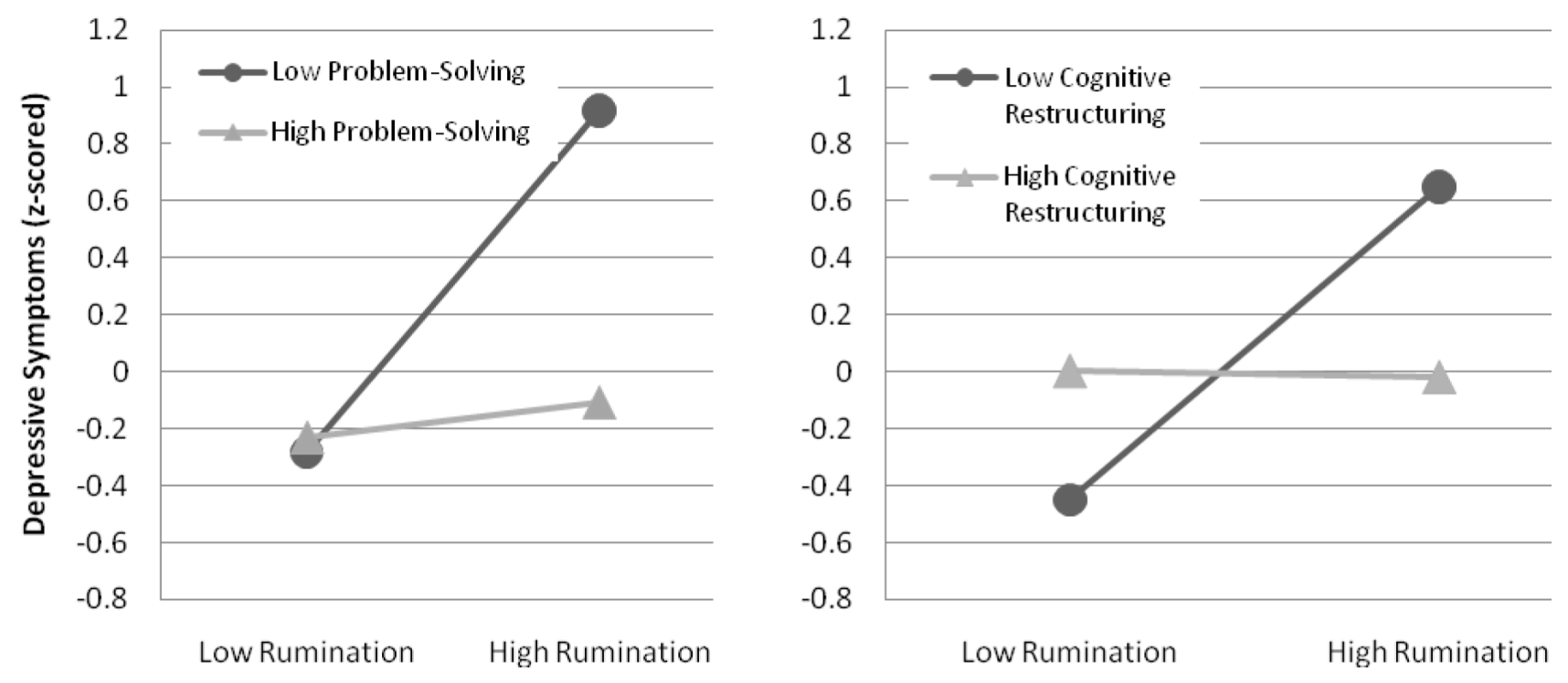

Figure 2.

Adaptive coping by rumination predicting depressive symptoms in nondepressed women 

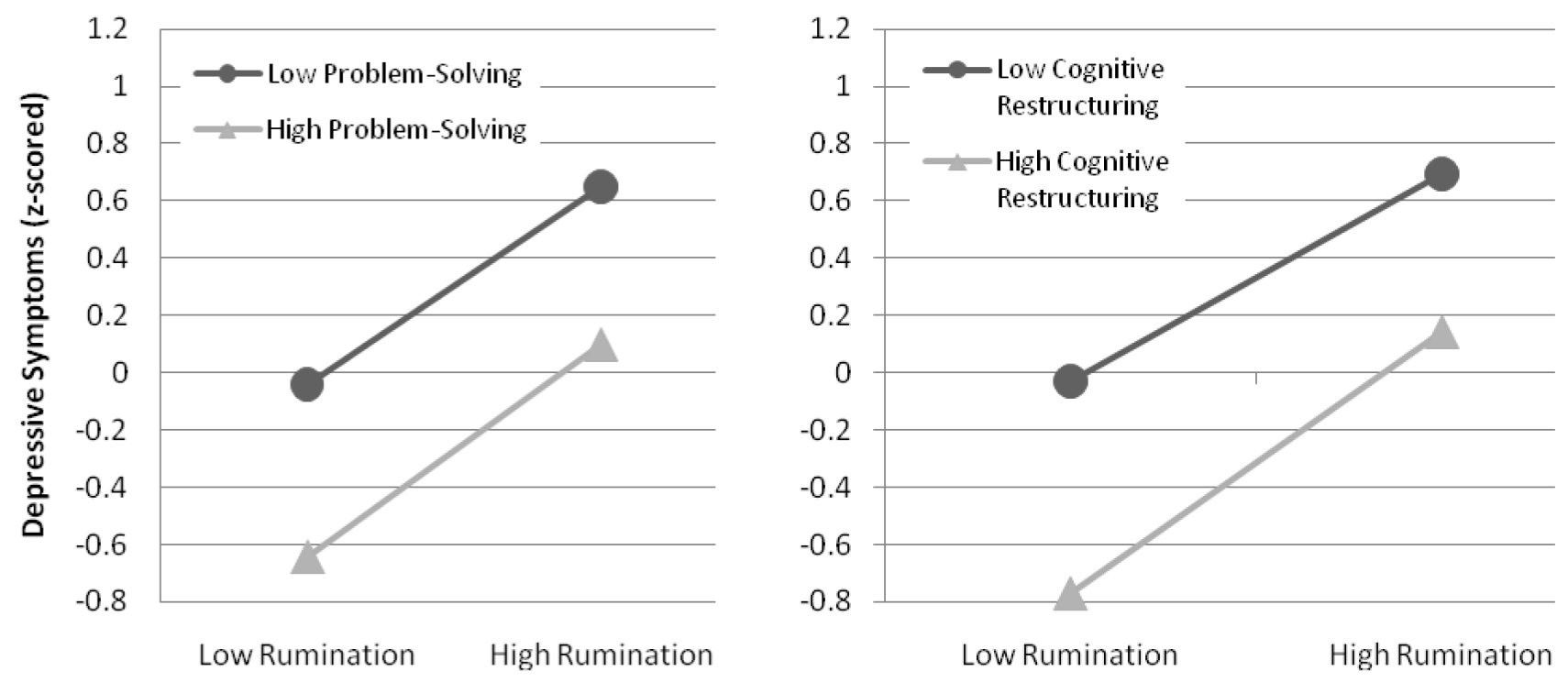

Figure 3.

Adaptive coping by rumination predicting depressive symptoms in depressed women 


\section{Table 1}

Group Differences in Included Variables

\begin{tabular}{|c|c|c|c|}
\hline & $\begin{array}{l}\text { Low-Risk Girls } \\
\text { Mean (SD) }\end{array}$ & $\begin{array}{l}\text { High-Risk Girls } \\
\text { Mean (SD) }\end{array}$ & $t$-tests \\
\hline Age & $12.1(1.5)$ & $12.2(1.5)$ & $t(145)=.69, p>.10$ \\
\hline Depressive Symptoms & $1.5(2.0)$ & $2.5(2.4)$ & $t(140)=2.51, p<.05$ \\
\hline \multicolumn{4}{|l|}{ Adaptive Coping $a$} \\
\hline Primary Control & $2.5(0.6)$ & $2.5(0.5)$ & $t(131)=0.50, p>.10$ \\
\hline Secondary Control & $2.4(0.5)$ & $2.3(0.5)$ & $t(131)=0.88, p>.10$ \\
\hline \multirow[t]{2}{*}{ Maladaptive Coping $a$} & $1.6(0.4)$ & $1.8(0.4)$ & $t(131)=3.05, p<.01$ \\
\hline & $\begin{array}{l}\text { Nondepress } \\
\text { Women } \\
\text { Mean (SD) }\end{array}$ & $\begin{array}{l}\text { Depressed } \\
\text { Women } \\
\text { Mean (SD) }\end{array}$ & $t$-tests \\
\hline Age & $27.2(7.0)$ & $27.7(6.6)$ & $t(78)=0.33, p>.10$ \\
\hline Depression & $1.4(2.1)$ & $33.1(9.2)$ & $t(78)=21.6, p<.001$ \\
\hline \multicolumn{4}{|l|}{ Adaptive Coping } \\
\hline Problem-Solving Coping & $23.8(5.9)$ & $18.8(5.8)$ & $t(78)=3.79, p<.001$ \\
\hline Cognitive Restructuring & $23.6(4.8)$ & $19.4(5.1)$ & $t(78)=3.75, p<.001$ \\
\hline \multicolumn{4}{|l|}{ Maladaptive Coping } \\
\hline Rumination & $15.7(4.1)$ & $27.6(5.0)$ & $t(78)=11.72, p<.001$ \\
\hline
\end{tabular}

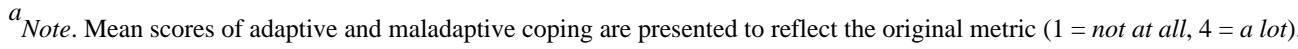




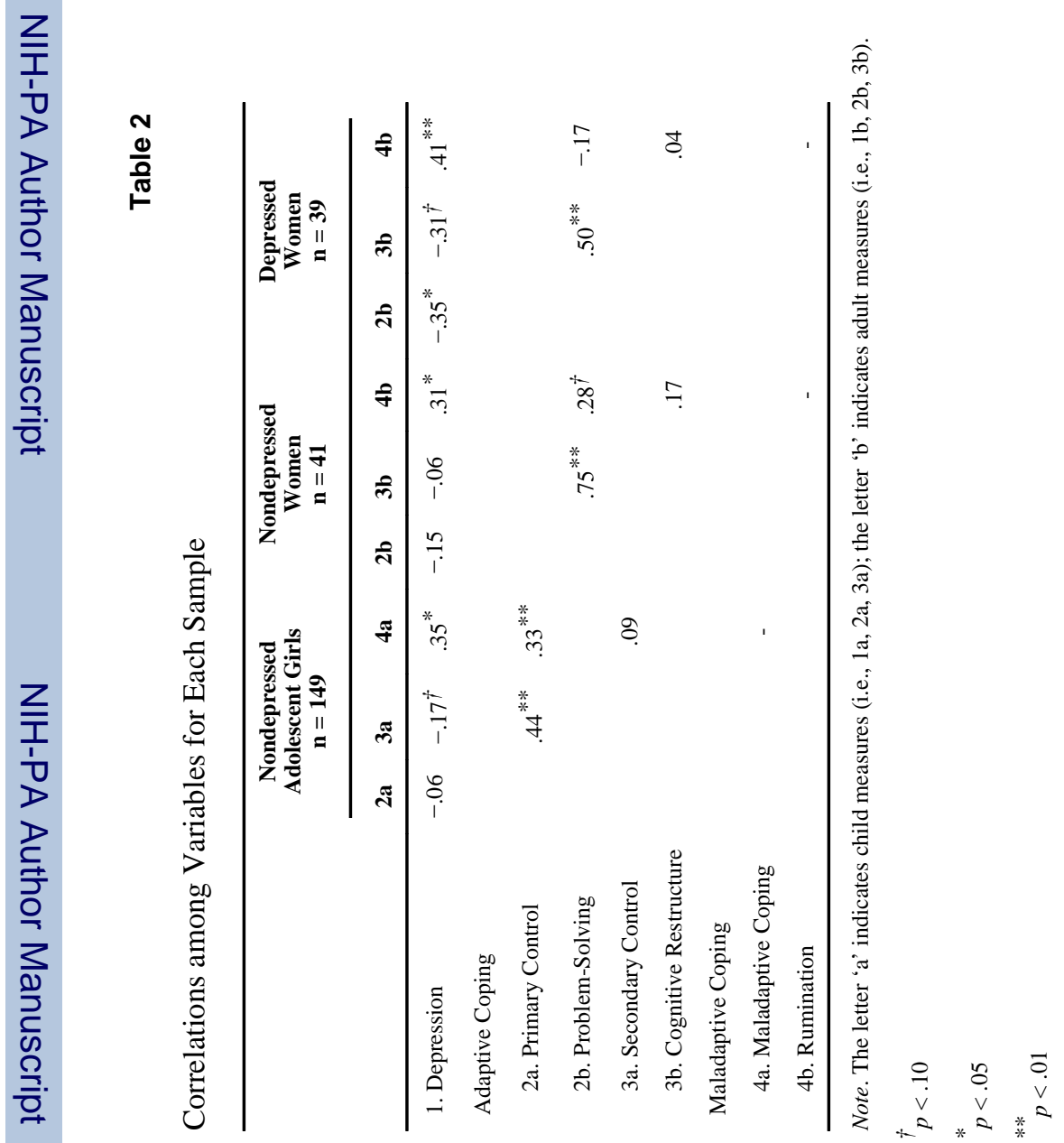

Behav Res Ther. Author manuscript; available in PMC 2011 June 1. 


\section{Table 3}

Hierarchical Linear Regressions Predicting Depressive Symptoms in the Sample 1: Nondepressed Adolescent ( $\mathrm{n}=149)$

\begin{tabular}{|c|c|c|}
\hline $\begin{array}{l}\text { Coping / Step \& predictor } \\
\text { variables }\end{array}$ & $\begin{array}{c}\text { Primary Control } \\
\text { Coping }\end{array}$ & $\begin{array}{l}\text { Secondary Control } \\
\text { Coping }\end{array}$ \\
\hline 1 & $\mathrm{~F} \Delta(2,127)=10.76, \mathrm{R}^{2}=.15^{* *}$ & $\mathrm{~F} \Delta(2,127)=11.54, \mathrm{R}^{2}=.15^{* *}$ \\
\hline Adaptive Coping & $\beta=-.17, t=-1.97^{\dagger}$ & $\beta=-.19, t=-2.30^{*}$ \\
\hline Maladaptive Coping & $\beta=.39, t=4.59^{* *}$ & $\beta=.36, t=4.34^{*}$ \\
\hline 2 & $\mathrm{~F} \Delta(1,126)=20.16, \Delta \mathrm{R}^{2}=.12^{* *}$ & $\mathrm{~F} \Delta(1,126)=3.71, \Delta \mathrm{R}^{2}=.02^{\dagger}$ \\
\hline Adaptive Coping by & $\beta=-.35, t=-4.49^{* *}$ & $\beta=-.16, t=-1.93^{\dagger}$ \\
\hline \multicolumn{3}{|l|}{ Maladaptive Coping } \\
\hline \multicolumn{3}{|l|}{${ }^{\dagger} p=.056$} \\
\hline \multicolumn{3}{|l|}{$*{ }^{*}<.05$} \\
\hline$* * * 0.01$ & & \\
\hline
\end{tabular}




\section{Table 4}

Hierarchical Linear Regressions Predicting Depressive Symptoms in Sample 2: Nondepressed Adults ( $\mathrm{n}=41)$

\begin{tabular}{|c|c|c|}
\hline $\begin{array}{l}\text { Coping / Step \& predictor } \\
\text { variables }\end{array}$ & $\begin{array}{l}\text { Problem-Solving } \\
\text { Coping }\end{array}$ & $\begin{array}{c}\text { Cognitive } \\
\text { Restructuring }\end{array}$ \\
\hline 1 & $\mathrm{~F} \Delta(2,38)=3.58, \mathrm{R}^{2}=.16^{*}$ & $\mathrm{~F} \Delta(2,38)=2.07, \mathrm{R}^{2}=.10$ \\
\hline Adaptive Coping & $\beta=-.26, t=-1.65$ & $\beta=.004, t=.03$ \\
\hline Maladaptive Coping & $\beta=.39, t=2.49^{*}$ & $\beta=.31, t=2.00^{\dagger}$ \\
\hline 2 & $\mathrm{~F} \Delta(1,37)=4.18, \Delta \mathrm{R}^{2}=.09^{*}$ & $\mathrm{~F} \Delta(1,37)=2.98, \Delta \mathrm{R}^{2}=.07 \dagger$ \\
\hline Adaptive Coping by & $\beta=-.30, t=-2.04^{*}$ & $\beta=-.27, t=-1.73^{\dagger}$ \\
\hline \multicolumn{3}{|l|}{ Maladaptive Coping } \\
\hline \multicolumn{3}{|l|}{${ }^{\dagger} p<.10$} \\
\hline \multicolumn{3}{|l|}{${ }^{*} p<.05$} \\
\hline$* * \quad p<.01$ & & \\
\hline
\end{tabular}




\section{Table 5}

Hierarchical Linear Regressions Predicting Depressive Symptoms in Sample 3: Depressed Adults $(n=39)$

\begin{tabular}{|c|c|c|}
\hline $\begin{array}{l}\text { Coping / Step \& predictor } \\
\text { variables }\end{array}$ & $\begin{array}{l}\text { Problem-Solving } \\
\text { Coping }\end{array}$ & $\begin{array}{c}\text { Cognitive } \\
\text { Restructuring }\end{array}$ \\
\hline 1 & $\mathrm{~F} \Delta(2,36)=5.99, \mathrm{R}^{2}=.25^{* *}$ & $\mathrm{~F} \Delta(2,36)=6.83, \mathrm{R}^{2}=.28^{* *}$ \\
\hline Adaptive Coping & $\beta=-.29, t=-1.94^{\dagger}$ & $\beta=-.32, t=-2.27^{*}$ \\
\hline Rumination & $\beta=.37, t=2.49^{*}$ & $\beta=.43, t=3.01^{* *}$ \\
\hline 2 & $\mathrm{~F} \Delta(1,35)=0.01, \Delta \mathrm{R}^{2}=.00$ & $\mathrm{~F} \Delta(1,35)=0.17, \Delta \mathrm{R}^{2}=.00$ \\
\hline Adaptive Coping by & $\beta=.01, t=0.08$ & $\beta=.06, t=0.42$ \\
\hline Rumination & & \\
\hline \multicolumn{3}{|l|}{${ }^{\dagger} p<.10$} \\
\hline \multicolumn{3}{|l|}{$* x<.05$} \\
\hline$* * \quad p<.01$ & & \\
\hline
\end{tabular}

